\title{
Modern Western Ecological Aesthetics from the Perspective of Aesthetics
}

\author{
Xiaofeng Wang* \\ Henan Polytechnic Institute, Nanyang, Henan, China \\ *Corresponding Author.
}

\begin{abstract}
:
Aesthetics is the study of people's perception and experience of heaven, earth and man and all things. Environment and landscape are the most important perceptual manifestation of ecosystem. How this perceptual manifestation affects human mind needs to be answered by aesthetics. It is not only possible but also necessary to study ecosystem from the perspective of aesthetics. Taking the ecological aesthetics of the English world as the main research object, this paper studies the three main approaches to the construction of western ecological aesthetics, which are philosophical speculation, ecological art theory and environmental practice. This study shows that: the interaction between ecological aesthetics and ecological art makes ecological aesthetics become the universal aesthetics of all aesthetic objects (including environment and Art), so as to distinguish it from environmental aesthetics more clearly. Strengthening the interaction between aesthetics and ecological aesthetic experience can make the connotation of ecological aesthetics more profound and clear. The results of this study have a certain reference value for the study of modern western ecological aesthetics from the perspective of aesthetics.
\end{abstract}

Keywords: Aesthetics, Ecosystem, Western Ecological Aesthetics, Ecological Art.

\section{INTRODUCTION}

Environmental aesthetics is an aesthetic trend of thought gradually produced under the unprecedented environmental crisis in the 20th century. It is an aesthetic paradigm based on environmental philosophy and environmental ethics. In environmental aesthetics, nature is not only the core of aesthetics, but also the starting point of ideas. Environmental aesthetics is the rediscovery of natural beauty, which emphasizes that nature should be the premise in the study of aesthetics [1-2]. On the basis of inheriting and absorbing the western classical aesthetics, environmental aesthetics tries to reflect and surpass the western aesthetic tradition.

Besides the connection between western environmental aesthetics and Chinese traditional ecological thought, the differences between them are also noteworthy. Some western environmental aestheticians have misunderstandings about Chinese traditional ecological thoughts [3]. For example, in the study of Confucianism, some environmental philosophers regard some of the "anti ecological" ideas in Confucianism as Confucian orthodoxy, and misunderstand the purpose of Confucianism in building social order, so they regard Confucianism as the separation of man and nature. This kind of thought is a misreading of Confucian orthodoxy, and does not fully understand all the spirit of Confucianism. It even ignores the deep thinking of the relationship between man and nature, and reduces the status of Confucian social ecological ideal. 
In a word, Chinese traditional ecological thought is different from western traditional view of nature. The acquisition of Chinese traditional thought helps to enrich ecological thought, and the interpretation of the relationship between man and nature in Chinese traditional philosophy is more inclusive.

\section{THE INTEGRATION OF ENVIRONMENTAL AESTHETICS AND CHINESE AND WESTERN VIEWS OF NATURE}

2.1 Hargrove and the distinction between Chinese and Western Environmental Aesthetics

In the Book Fundamentals of environmental ethics, from the perspectives of ecology, aesthetics and metaphysics, Hargrove deeply explores the origin of anti environment concept in ancient Greek philosophy, and then understands the formation and main content of anti nature concept in modern philosophy.

In his opinion, ancient Greece's simple understanding of the permanence, eternity and immutability of the world was contrary to the complex concept of non permanence, transience and dynamic change in ecological thought, and at the same time hindered the appreciation of natural beauty, which can be attributed to the imperfect metaphysical explanation of nature. On this basis, the dualism of material and spirit, the distinction between the first attribute and the second attribute in modern philosophy, then prompted most philosophers to ignore the protection of nature [4-6]. However, he also saw that the possibility of environmental view turning was still preserved outside the mainstream western traditional concept, and this non mainstream concept also provided the possibility for him to try to solve the western environmental crisis through Eastern civilization.

Hagrov's environmental ethics thought is inclined to "weak anthropocentrism", which is mainly reflected in his discrimination of the concept of right in environmental ethics [7]. He denied the existence of species rights, but acknowledged the intrinsic value of nature. He thinks that the source of the concept of right is the substitution of intrinsic value, and the second is the misunderstanding of the relationship between environmental ethics and animal welfare ethics. He does not support the value of non-human species with species rights, and does not support animal welfare ethics as the basis of environmental ethics, but he does not oppose animal welfare movement.

Hargrove's concept of environmental ethics is based on the western environmental aesthetics. In the foundation of environmental ethics, he tries to seek reasonable proof for the origin of modern environmental concept from western traditional culture [8]. Although Hargrove admits that there are some viewpoints in traditional western philosophy that hinder the development of modern environmental ethics, he still believes that Western civilization also has the basis of protecting nature [9]. "There is only one step from Whitehead's" friendly environment "to Leopold's" life community ", which does not need to resort to Oriental philosophy and religion [10]. He hoped that people would protect nature not because of utilitarianism and pragmatism such as economic value, but because of its beauty and interest. The interaction between ecological environment and ecological aesthetics is shown in Figure 1. 


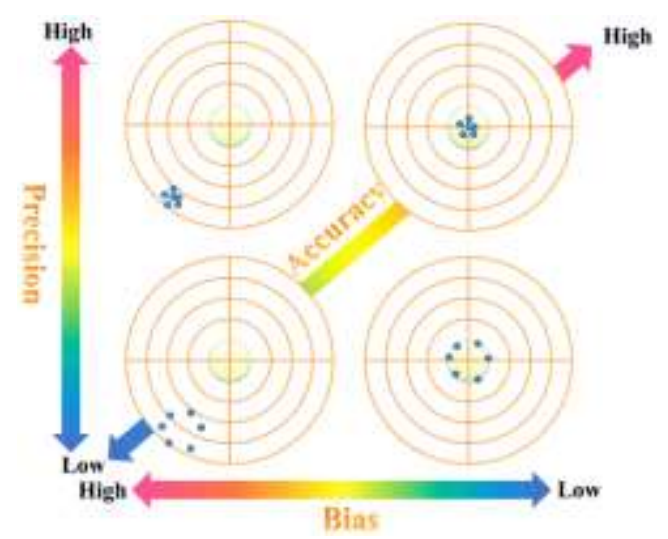

Fig. 1: The interaction between ecological environment and ecological aesthetics

\subsection{Shi huaize's acceptance of Taoist wisdom}

Shi huaize highly appreciated the eastern ecological concept including traditional Chinese thought. He mentioned the value of ancient Chinese thought to the modern world many times. Especially in the aspect of understanding the relationship between man and nature, Shi huaize thinks that the thoughts of Chinese thinkers such as Laozi (born in 604 BC), Confucius (551-478 BC), Mencius (372-289 BC), Zhuangzi (4th century BC) are the most in line with his ethics. He has a certain research on these wise men, and he almost completely agrees with the ancient Chinese thought from the ideological level.

In Shi huaize's view, both Western philosophers and Eastern thinkers hope to find a way that can not only protect the right to existence and freedom of all things, but also promote the spiritual closer between man and nature. Schweitzer believes that there can be an accommodation between man and the world, and that man's will does not conflict with the world's will. Human beings do not have to deprive other creatures of their rights or even threaten the whole world in order to obtain more survival rights. Human existence can establish a symbiotic relationship with all things.

Among the traditional Chinese thoughts, Shi huaize pays most attention to the survival wisdom and ecological thought of Taoism, especially the Taoist idea of the integration of human and world spirit and the equality of all things. In his view, the wisdom of Taoism can best reflect the environmental ethics of reverence for life.

Shi huaize has a deep understanding of the thoughts of Laozi and Zhuangzi. He compares Taoism with ancient Greek philosophy: "the Stoicism of Greece and China is essentially similar. The only difference between them is that the Greek stoicism originated from the developed logical thinking, while the Chinese stoicism originated from the underdeveloped but miraculously profound intuitive thinking. As Schweitzer said, Taoism does not emphasize complete logical speculation, but favors feeling and intuition and the way of understanding the world.

\section{THE PROMOTION OF CHINESE TRADITIONAL THOUGHT TO ENVIRONMENTAL AESTHETICS}

3.1 The realm of Buddhism and Taoism in Pepper's "Ecological Utopia"

Pepper believes that western traditional mysticism and eastern traditional wisdom can provide rich ideological resources for modern environmentalism, and there is rich ecological wisdom hidden in these ancient thoughts. Peper juxtaposed Taoism, Buddhism and modern environmentalism. There is a certain gap between them, but they all put nature at the center of their ideas. It is a common fault of environmentalists to 
confuse the oriental traditional culture with the traditional religious mysticism, because their research on the oriental traditional culture is not in-depth, they just want to find wisdom in the Oriental thought. In addition to the thinking pattern of western modern ideas, Oriental wisdom provides abundant resources for ecologists.

In peper's view, deep ecology is a comprehensive concept, which is as inclusive as nature. Any wisdom can find a place in it, especially those Eastern religious wisdom that can attract countless believers after thousands of years. Peper further believes that the concept advocated by deep ecology coincides with traditional Chinese thought, and has a close relationship with modern western knowledge and philosophy, which is just a critical inheritance of the latter. After reflecting on Descartes, Spinoza withdraws from the monism of holism. Peper compares it with Laozi's holism in Tao Te Ching. He believes that this idea "coincides with Laozi, the Chinese philosopher in the 6th century BC, who provides a perfect holistic cosmic perspective in Tao Te Ching". He explained Laozi's thought from the perspective of ecologism: "Tao is the reality hidden under the surface phenomenon. It never stops running, expanding and shrinking. Therefore, all the seemingly opposite things (female and male, heaven and earth, cold and heat) are really different aspects of the same thing. Just as Yin and yang are, it is necessary to stand in balance. ". He combined Oriental thought with modern western philosophy, thus leading to a new ecological philosophy.

Peper's ecological thought has a strong political color, and the utopian political ideal occupies the main position in his ecological thought. He hopes to realize the improvement of social system through ecological philosophy. Whether in the West or in the East, the thought of "Utopia" has a profound impact on social politics. From the beginning of Chinese traditional thought, Lao Tzu's ecological political ideal of "small country with few people" has affected the construction of Chinese and even Eastern thought, which is also in line with the dream of returning to the golden age in the West. This is an important reason why peper's ecological political philosophy can influence the cross-cultural environmental ethics.

3.2 Constructive postmodern philosophy and Chinese ecological thought

Constructive postmodernists hope to establish a relatively more reasonable new ethics which is more suitable for correcting the relationship between man and nature. It is different from traditional western ethics because the latter is "completely human-centered". Moreover, science and rationality have once become the only way for human beings to know the world, and perceptual experience has been rejected. Western modern rationality has formed a certain established discourse: "Just because European thought has been stereotyped, as long as we deviate slightly from the goal of science and technology, no matter how insignificant the deviation is, we will be convicted of going to the opposite side of science and technology, that is, irrational, instinctive and crazy mysticism". Relationship model of complexity, diversity and stability of ecological environment and ecological aesthetics is shown in Figure 2. 


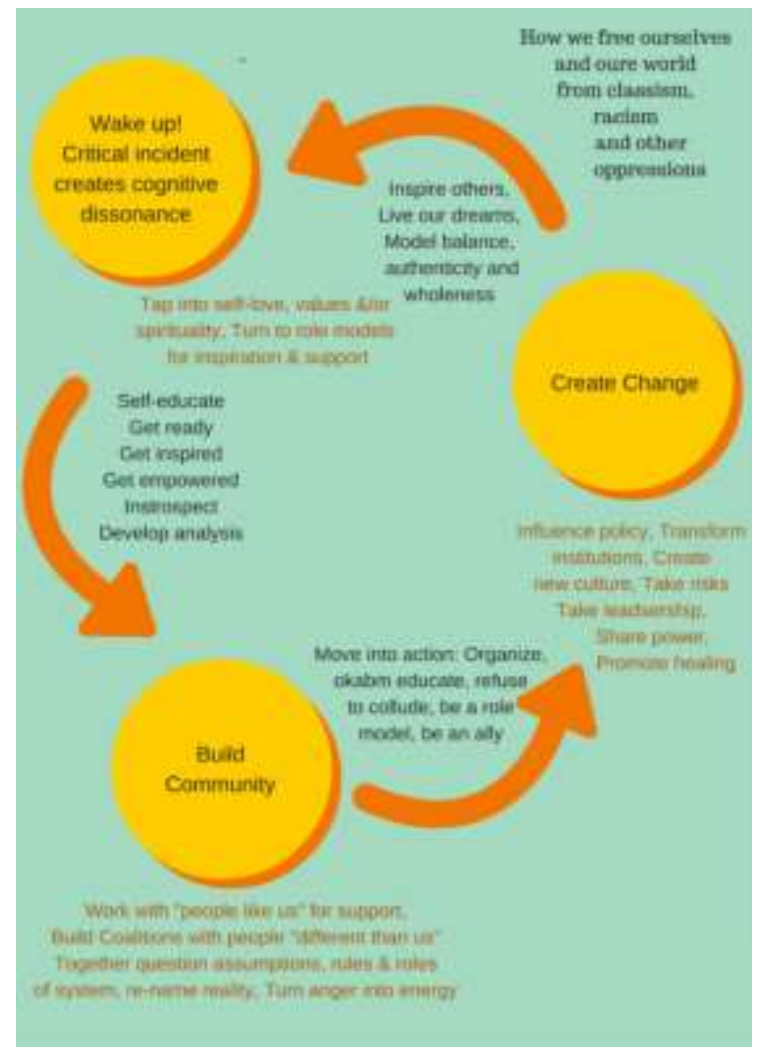

Fig. 2: Relationship model of complexity, diversity and stability of ecological environment and ecological aesthetics

The reflection of Constructive Postmodern thinkers on modernity and the reconstruction of theology promote the development of environmental philosophy and environmental ethics. From the point of view of the ultimate goal of ideas, Griffin is first a theologian, then a philosopher and ecological critic. His attention to ecological problems always carries strong religious feelings. However, outside religion, constructive postmodernism neither separates the traditions of the East and the west, nor stubbornly drives modern science out of the spiritual dimension.

Griffin believes that nihilism and paranormalism are the mainstream thinking about environmental problems in the upper class of the United States, and both of them are the root of the worsening environmental problems. Whitehead's thought not only reflects on this, but also points out the direction for the new environmental concept. Specifically speaking, the significance of Whitehead's thought for modern environmental philosophy is mainly reflected in three aspects: first, reflecting on modern rationality, that is, from disenchantment to Reenchantment; second, establishing the direction for environmental aesthetics, Whitehead's thought promotes the transformation of natural aesthetics; third, promoting environmental philosophy and ecological philosophy to actively absorb traditional oriental wisdom such as China.

\section{TOWARDS CROSS CULTURAL ENVIRONMENTAL AESTHETICS}

At present, the relationship between environmental aesthetics and ecological aesthetics has become the premise of the study of environmental aesthetics. There are some differences between the two aesthetic paradigms in the aspects of aesthetic starting point, conceptual perspective and ethical basis. It is very important to distinguish the two categories and determine their boundaries.

Arnold Berlin puts forward the concept of "participatory aesthetics" to try to solve the gap between 
environmental aesthetics and ecological aesthetics, and discusses the possibility of environmental aesthetics moving towards ecological aesthetics. He believes that Chinese traditional thoughts can play an important role in this transformation. Tucker and other scholars directly extract wisdom from traditional Chinese aesthetics to realize the combination of environmental aesthetics and ecological aesthetics. Due to the intervention of Chinese traditional ecological thoughts, environmental aesthetics and ecological aesthetics gradually began to play a cross-cultural variation.

4.1 The intervention of Chinese ecological thought and the development of western environmental aesthetics

The establishment of environmental aesthetics is not the end of aesthetics. With the development of environmental aesthetics, the aesthetic way of only examining the natural beauty and completely separating the relationship between man and nature is more and more unsuitable to the changes of environment. For example, the concept of "human discipline" in ecological criticism has revolutionary significance for the traditional natural aesthetics. Under the influence of new ideas, ecological aesthetics has gradually emerged and began to replace the original single environmental aesthetic model.

Another characteristic of ecological aesthetics is how to distinguish the appreciator from the aesthetic object. Starting from biocentrism, ecological ethics regards natural laws as the yardstick of morality. Influenced by it, ecological aesthetics requires that the whole nature be regarded as the aesthetic object, or even as the core of aesthetics. The relationship between man and all things is the basis of aesthetics. In the process of aesthetics, the subject and object of aesthetics are constantly changing, and even change with each other.

From the point of view of starting point, ecological aesthetics is based on ethical norms, while environmental aesthetics is based on aesthetics. The former pays attention to the spiritual problems of human beings, environmental problems and the reconstruction of the relationship between human beings and nature, while the latter pays more attention to the beauty of nature and its related problems. How to deal with the relationship between man and everything will directly affect the understanding of natural beauty. Whether people are included in the natural aesthetic, whether the existence of people will affect the natural beauty, and whether the natural beauty of no one exists need to be further explored. The theory that environmental aesthetics regards nature as an uninhabited environment has also been questioned.

\subsection{Cross cultural reflection on Environmental Aesthetics}

From the current situation of environmental aesthetics research, there are still many problems to be discussed about the acceptance of western environmental aesthetics to Chinese traditional aesthetics and the attitude of western environmental aestheticians towards Chinese traditional view of nature. On the one hand, it is related to the research level of western environmental aestheticians on Chinese traditional thought, on the other hand, it is also related to the development and change of Chinese traditional environmental concept itself.

As far as Chinese traditional culture itself is concerned, different philosophies, such as Confucianism, Buddhism and Taoism, have different understandings of the relationship between man and nature. There are also differences between different philosophies on the value of man's existence, man's position in nature, and the relationship between man and non-human beings and non living things. These viewpoints ultimately affect the aesthetic problems of nature. Like environmental aesthetics, Chinese traditional ecological thought also presents some "complexity" characteristics. Confucianism, Buddhism and Taoism hold different views on natural problems. In the process of the development of Chinese traditional culture, the relationship 
between man and nature is not invariable. As far as the aesthetics of literature and art is concerned, there are many forms in the same art form. The construction process of ecological aesthetics is shown in Figure 3.

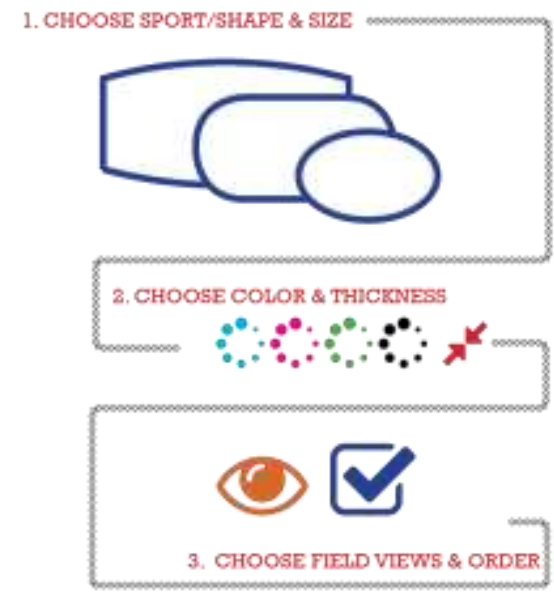

Fig. 3: The construction process of ecological aesthetics

From the development history of Chinese traditional aesthetics, the status of nature in art is gradually rising. Taking traditional painting as an example, landscape painting gradually appeared after Wei and Jin Dynasties. Before that, figure painting occupied the main body of traditional Chinese painting, and landscape painting really introduced nature into art. Since the Tang Dynasty, landscape painting has paid more and more attention to the expression of natural beauty. "The spirit of Chinese art can be said to have completed the form required by its own character through the emergence of ink painting and light colored landscape in the Tang Dynasty.". Chinese traditional scholars discovered the real value of landscape early. In terms of philosophy of life and aesthetics, landscape is integrated with life and society.

\section{CONCLUSION}

In a word, from the perspective of aesthetic history, environmental aesthetics is not exclusively in the field of modern aesthetics. If it is traced up, from Romanticism, classicism to ancient Greek aesthetics, it has been continuing to pay attention to natural beauty, but the status of natural beauty in each historical period is different. In the field of traditional Chinese aesthetics, natural beauty has been paid more attention in every historical period, and the position of nature occupies a more important position in aesthetics. Since modern times, with the change of natural environment and the expansion of human activities, more and more attention has been paid to nature. The development of life science also promotes human understanding of nature. Natural aesthetics becomes more and more complex. Scientific knowledge, traditional aesthetic experience and environmental problems all affect the aesthetic orientation, interest and attitude.

\section{REFERENCES}

[1] Chen WangHeng. Ecological aesthetics and its philosophical basis. Journal of Shaanxi Normal University (PHILOSOPHY AND SOCIAL SCIENCES EDITION), 2001, 030 (002): 5-10

[2] Wang Xi. The dilemma and boundary of ecological aesthetics research. Journal of East China Normal University (PHILOSOPHY AND SOCIAL SCIENCES), 2007 (03): 58-63

[3] Zeng fanren. Several important issues in current ecological aesthetics research. Jiangsu Social Sciences, 2004, 2004 (002): 204-206 
[4] Nie Zhenbin. Thoughts on ecological aesthetics. Journal of Guizhou Normal University (SOCIAL SCIENCE EDITION), 2004 (1): 92-95

[5] Cheng Xiangzhan. Ideological basis and theoretical progress of American Ecological Aesthetics. Literature review, 2009 (01): 71-76

[6] Zeng fanren. Ecological Aesthetics: a new ecological ontology aesthetics in the postmodern context. Journal of Shaanxi Normal University (PHILOSOPHY AND SOCIAL SCIENCES EDITION), 2002, 31 (003): 5-16

[7] Zeng fanren. Ecological aesthetics in the perspective of contemporary ecological civilization. Literature review, 2005 (4): 48-55

[8] Zeng fanren. Towards a deeper and more mature study of ecological aesthetics in China. Oriental series, 2005, 000 (002): $2-8$

[9] Huang Danhui. Aesthetic research on Contemporary Western Ecological Architecture. China Art Museum, 2008 (06): 11-15

[10] Zeng fanren. Basic categories of contemporary ecological aesthetics. Literature and art studies, 2007 (04): 1522 